\title{
ATOS DE FICCIONALIZAR E EMANCIPAÇÃO DO LEITOR: PARA ALÉM DO OXIGÊNIO
}

\author{
FICTIONALIZING ACTS AND EMANCIPATION OF THE \\ READER: BEYOND OXYGEN
}

\author{
Carmen Sevilla Gonçalves dos SANTOS*
}

\begin{abstract}
Resumo: Este artigo discorre sobre a relação entre os atos de ficcionalização em leitura literária e a emancipação do leitor. Para tanto, iniciamos pelo cotejo entre a Estética da Recepção e a Teoria do Efeito Estético, no que se refere aos seus aspectos teóricos e metodológicos. Esse paralelo nos revelou, antes, o caráter suplementar de tais teorias do que uma complementaridade entre elas, como outrora propagado. Na sequência, circunscrevemos a discussão sobre os atos de ficcionalizar e a emancipação do leitor no entre-lugar heurístico formulado tanto pela Teoria Histórico-Cultural — do psicólogo russo Lev. S. Vigotski - como pela Teoria do Efeito Estético, e seu prolongamento, a Antropologia Literária - ambas de Wolfgang Iser. A seguir, dissertamos sobre a experiência estética, a importância da incursão do leitor real nessa experiência e a biunívoca relação entre os conceitos fundantes das teorias vigotskiana e iseriana, mostrando como a primeira serve à segunda. Por fim, a argumentação culmina na relevância do ato de mapear a experiência estética como chave para autoconsciência dos processos cognitivos e metacognitivos vivenciados pelo leitor de leitura ficcional ao construir sentido. Essa autoconsciência pode viabilizar o manejo de tais processos, favorecendo o alcance de níveis mais complexos de emancipação. A compreensão da experiência estética é — do nosso ponto de vista — determinante para fomentar uma leitura emancipadora, aproximando-nos, ainda que minimamente, das muitas possibilidades do que somos.
\end{abstract}

Palavras-chave: Atos de ficcionalização. Teoria do efeito estético. Antropologia literária. Teoria histórico-cultural. Emancipação.

Abstract: This paper discusses the relationship between the acts of fictionalization in literary reading and the emancipation of the reader. For this, first, it makes a comparison of the Aesthetics of Reception and the Theory of the Aesthetic Effect, regarding their theoretical and methodological aspects. This parallel has revealed the supplementary character of such theories rather than a complementarity between them, as previously propagated. Then, it discusses the acts of fictionalization and the emancipation of the reader in the heuristic in-betweeness formulated by both the Historical-Cultural Theory (Vigotski) and by the Theory of the Aesthetic Effect, and its extension, Literary Anthropology (Iser). Next, it approaches the aesthetic experience, the importance of the incursion of the concept of real reader in this experience and the two-way relationship between the founding Vigotskian's and Iserian's theoretical concepts, presenting how the first serves the second. Finally, it argues for the relevance of the act of mapping aesthetic experience as a key to self-awareness of the cognitive and metacognitive processes experienced by the reader in fictional reading when building meaning. This self-awareness can enable the management of such processes, favoring the achievement of more complex levels of emancipation. The understanding of the aesthetic experience is - from our point of view - crucial to foster an emancipatory reading, approaching, even if minimally, the many possibilities of what we are.

Keywords: Fictionalizing acts. Theory of aesthetic response. Literary anthropology. Historical-Cultural theory. Emancipation.

\footnotetext{
* Professora do Programa de Pós-Graduação em Letras da Universidade Federal da Paraíba (UFPB). Doutorado em teoria da literatura pela Universidade Federal de Pernambuco (UFPE). E-mail: csevillags@gmail.com.
} 


\section{Considerações iniciais: um lugar para fingir}

Como se explica a relevância social de uma reflexão sobre o ato de ficcionalizar em literatura quando atravessamos uma pandemia? Milhares de pessoas morrem, outros milhares se aprofundam na miséria, sistema de saúde entra em colapso, valores morais e direitos humanos são (re)negociados dentro do contexto de um Brasil politicamente sem rumo ou de rumo catastrófico. Nesse quase apocalíptico panorama, há espaço para ficcionalizar, enredar-se em atos de fingir, tais quais a literatura exige? Sim, acreditamos que há. Essa crença/esperança é um dos principais combustíveis para o artigo em pauta.

Precisa haver lugar para a ficcionalização, ou seja, para o fingimento, que permite nosso envolvimento na busca pelo sentido. Isso porque carecemos de sentido para o que somos e para aquilo que fazemos. Nós precisamos ficcionalizar para continuar fazendo o que fazemos e sendo quem somos. Ficcionalizar é, portanto, uma atividade humanizadora sucedida de vários modos e em diversos setores de nossas vidas. Wolfgang Iser vê os atos de ficcionalizar como uma necessidade humana (1978, 1993a, 1993b, 1999). Se buscar sentido é uma atividade antropológica e, quando lemos ficção, fazemos isso de modo notório, ficcionalizar é, por conseguinte, antropológico.

Ao que parece, em dias de isolamento social, quarentena, confinamento, lockdown, as ficcionalizações das pessoas se constituem alento para a alma. Criam histórias para interpretarem o que não entendem sobre o vírus, a vacina, a morte, a cura, a vida, os valores, os protocolos das autoridades; igualmente, ficcionalizam através de lives, em redes sociais. Ficcionalizam sobre música, filmes, literatura, fé, crenças, superstições, religiões. Cada pessoa ficcionaliza de acordo com seu entorno social. Ficcionalizar não pressupõe classe social; os modos de fazê-lo podem se diferenciar, encontrar outros suportes, mas todos nós o vivenciamos. Preencher, articular, interpretar, traduzir, negar, negociar vazios na busca de sentido - quer sejam existenciais, quer sejam na arte — nos civiliza.

Ao encontro do projeto da Antropologia Literária iseriana, Candido diz que a literatura “[...] é fator indispensável de humanização, e, sendo assim, confirma o homem na sua humanidade, inclusive porque atua em grande parte no subconsciente e no inconsciente" (2011, p. 177).

Afunilaremos, neste artigo, a ficcionalização que empreendemos para construção do sentido ao nos embrenharmos em um texto ficcional. Assim, nesses obnubilados tempos de crise sanitária, econômica e política, com suas drásticas ingerências na nossa vida concreta e psicológica, a discussão da relevância dos atos de ficcionalizar — como alguém 
preenche/articula/interpreta/nega/negocia os vazios em um texto literário — e sua relação com a emancipação afetiva, cognitiva, estética e política do leitor, pode ser vista como um rito de amorosa resistência. Mais do que nunca, em tempos de crise, emancipar-se é preciso.

\section{Entre-lugar teórico dos atos de ficcionalização e emancipação do leitor}

A relação entre atos de ficcionalizar e emancipação do leitor ora desenvolvida neste artigo está circunscrita sob a umbrella da Teoria da Recepção e do Efeito Estético, cunhada por Hans Robert Jauss (1994) ${ }^{1}$ e Wolfgang Iser (1971), respectivamente.

Atinamos, contudo, para o fato de que as duas teorias, a nosso ver, não são complementares, como outros ainda assim as consideram e também nós outrora pensamos, posto que cada uma delas tem objetivos distintos que, ao serem atingidos, açambarcam os principais construtos e elementos epistemológicos que as concebem, arrematando, embora não de modo impeditivo de posterior evolução, sua chancela no cenário da teoria e crítica literária.

Em outras palavras, a Estética da Recepção possui um veio próprio, tanto teórico quanto metodológico, portanto, não se faz necessário analisar o efeito individual de um texto literário para compreender a sua recepção. Por meio de dados documentais advindos do destinatário ou comunidade leitora, pode-se avaliar como a obra foi recebida sincrônica e anacronicamente (JAUSS, 1994). A Teoria do Efeito Estético, por sua vez, pode responder à questão de como o leitor individual constrói o sentido ou o que acontece na sua mente ao ler um texto ficcional (ISER, 1974). Depreendemos, então, que as duas teorias são paralelas e pertencem a um mesmo ideário, no que concerne ao fato de se interessarem pela interação texto e leitor.

É possível ainda, a nosso ver, uma terceira via: estudar a recepção de obras literárias de um ponto de vista do leitor coletivo, com esteio na teoria jaussiana, e daí partir para o efeito no leitor individual, como elucubrou Iser (1978). O inverso, analisar o efeito da leitura de textos literários em indivíduos e, desse ponto, abrir para a recepção de uma comunidade em um dado tempo e espaço, também é perfeitamente possível. Se ambas as teorias fossem complementares, essa ida e vinda metodológica seria obrigatória. Não é.

Consideramos fundamental, à vista disso, sobrelevar o caráter suplementar das duas teorias e, portanto, o terceiro caminho ora proposto para abordagem do estudo da recepção de textos literários parece pertinente: partir da análise da comunidade leitora para o leitor individual ou do sujeito leitor para a comunidade. Analisar a recepção e depois o efeito ou o efeito e, posteriormente, a recepção. Desse modo, entendemos a Estética da Recepção e a Teoria

\footnotetext{
${ }^{1}$ Primeira edição em 1967.
} 
do Efeito Estético como suplementares uma à outra, e isso é diferente de complementaridade. Dito isso, fechamos ainda mais o zoom de nossa perspectiva, embasando a presente discussão no pensamento iseriano, ao qual nos dedicamos desde 2003.

É fundamental destacar que o indivíduo considerado por Iser, em sua teoria, faz referência ao conceito de leitor implícito, ou seja, às estruturas textuais, tornando a relação texto-leitor uma metáfora, pois o leitor, para ele, também está inscrito no texto. Ora, o leitor implícito não é, como muitos pensam, uma pessoa, mas a estrutura do texto repleta de vazios que permite a entrada de um leitor real. Esse, por sua vez, ao penetrar nessa seara, formula o sentido do texto. O realce sobre o leitor iseriano nos impeliu a elaborar o conceito de leitor real como aquele capaz de entrar em implicitude, isto é, de atualizar as estruturas textuais, objetivando a obra. Sem a entrada de um leitor real que aceite a implicitude do texto, ou seja, que concorde em interagir com sua estrutura para construir o sentido, não existe obra. A obra só existe na interação, ela é virtual, dura o tempo da experiência estética do leitor real posto em implicitude com o texto ficcional.

Evidentemente, do lugar da teoria e crítica literárias, não há como se pensar um leitor real, não cabe no seu escopo. Para isso, é preciso a entrada de outra ciência, nesse caso, a psicologia cognitiva. Assim, utilizamos a Teoria Histórico-Cultural, formulada por L. S. Vigotski para delinear o "leitor de carne e osso", de modo que o diferenciasse do leitor ideal, aquele que sempre se põe adequadamente em implicitude (SANTOS, 2007; 2009; 2011; 2014). Detalharemos esse delineamento na próxima seção.

Pôr-se adequadamente em implicitude significa dizer que esse leitor tem condições cognitivas de - a partir do que há de familiar no texto — articular as diferentes perspectivas textuais, formulando, pois, o objeto estético, ou seja, emancipando-se.

A Teoria Histórico-Cultural, de Vigotski, impulsionou-nos na direção da Teoria do Efeito Estético e, de seu prolongamento, a Antropologia Literária. Assim, é com suporte nessa tríade teórica que discutimos a relação entre atos de ficcionalizar e emancipação do leitor.

\section{Experiência estética e concepção de leitor real: em busca da autoconsciência do fingimento}

Pinçando ainda mais a nossa perspectiva sobre o tema, ousamos dizer: a teorização iseriana sobre o que acontece na mente de quem lê pode — salvaguardadas as devidas peculiaridades - perpassar a análise da recepção de obras literárias também contemporâneas.

Depreendemos dessa contingência que os eventos sucedidos em nossa mente ao ler ficção passam por padrões de semelhança a despeito de características do texto e do leitor. Esse padrão 
permite aos textos literários de todos os tempos possibilitarem a entrada de um leitor real que se ponha em implicitude e construa seus sentidos. Não há sentidos cristalizados. Múltiplos sentidos são possíveis, mas não qualquer sentido. Ele, o sentido, precisa estar ancorado no texto, e, desse modo, se desprende das interpretações meramente impressionistas ou das super interpretações, no dizer de Umberto Eco (1993).

Os estudos que desenvolvemos nos últimos anos de modo solipsista (SANTOS, 2007, 2009, 2014), mas também junto a alunos da graduação e da pós-graduação, nos ajudaram a delinear um possível caminho para mapeamento da experiência estética do leitor. Essa experiência dentro da visão iseriana não é propiciada exclusivamente pela estrutura do texto, nem pelo processo de leitura, mas por meio da interação entre leitor e texto. Interação essa compreendida como metáfora, conforme já assinalado neste artigo, pois, de fato, as alterações mútuas que nela acontecem diferem, demasiadamente, das interações face a face.

Assim, a experiência dura enquanto acontece a leitura. Essa característica da experiência estética nos impõe problemas de várias ordens, mas, para escopo deste artigo, selecionamos a questão de ordem metodológica. Como captar a experiência estética? Aliás, captar não seria um verbo de naipe reificador e, por conseguinte, inadequado para tal associação? Afinal, a experiência não é algo palpável. Reformulemos: como analisar a experiência estética? É possível analisar o que se passa na mente de outrem? A propósito, até a nossa experiência estética é abundantemente abstrata, complexa e imiscuída em processos nem sempre conscientes. Se não podemos analisar tal experiência, como compreendê-la e, consequentemente, mediá-la? Basta ao próprio texto ser o mediador, como sinalizou Larrosa em sua Pegagogia profana (2006)? Como docentes, precisamos organizar situações didáticas que envolvam a experiência estética, albergando não apenas sua fluidez, mas as idiossincrasias cognitivas e metacognitivas dos alunos. Como motivar experiências estéticas se elas são apenas passíveis de auto-observação? Como entendê-las se, a cada leitura, tais experiências se modificam?

Wolfgang Iser, em The Implied Reader (1974) e The act of reading (1978), utiliza sua própria experiência acerca de textos literários de vários autores para associar a seus pressupostos teóricos. Ao passo que ele foi adentrando no campo da Antropologia Literária, contudo, começou a abandonar os exemplos literários (Cf. SCHWAB, 1999). Por ocasião do VII Colóquio UERJ, em 1996, Iser, em relação a isso, respondeu à Gabrielle Schwab nos seguintes termos: "Numa resposta bem-humorada, poderia adaptar uma frase de [Walter] Pater. Uma vez, ele disse: 'Não corrompo mais minhas páginas com notas ao pé da página'. Pois bem, "não corrompo mais teorias com exemplo"”. 
Compreendemos que, do veio epistemológico, no qual a Teoria do Efeito Estético e sua extensão, a Antropologia Literária, se encontram, não há como efetivar o ato de leitura minuciosa e brilhantemente descrito por Iser. O que falta, então?

Faltam bases de dois níveis. O primeiro seria teórico, evidentemente, e o segundo, procedimental. Iser (2006) diferenciou teoria de metodologia, afirmando que a primeira faz referência a premissas e pressupostos de compreensão de uma dada situação, enquanto a outra se interessa por ferramentas e instrumentais de procedimento. Essa diferenciação nos ajuda a entender que a teoria não nos dá a ferramenta diretamente, seus pressupostos, todavia, suportam sua elaboração.

Desde 2014, temos investido na criação de um Roteiro Didático Metaprocedimental (RDM) que inclui os conceitos iserianos e a incursão do leitor real suportado pela teoria vigotskiana (SANTOS, 2014, 2015, 2017, 2018, 2019). Tal roteiro favorece a mediação de um mapeamento da experiência estética e fornece subsídios também para o ensino de leitura literária rumo à emancipação do leitor. Embora descrever e explicar o RDM esteja fora dos limites deste artigo, podemos discutir abaixo as reverberações de seus pressupostos.

Mapear a experiência estética é a chave para tomarmos consciência dos processos cognitivos e metacognitivos que passamos ao lermos um texto literário e construirmos sentido. Ao mapearmos nossa experiência estética, tornamo-nos autoconscientes dos eventos que ocorrem em nossa mente. Essa autoconsciência possibilita uma maior capacidade para manejarmos tais processos e alcançarmos níveis mais elevados de emancipação. Por sua vez, essa emancipação é cognitiva, estética, social, afetiva. A compreensão da experiência estética é, do nosso ponto de vista, fundamental não apenas para propiciar a mediação de uma leitura emancipadora, mas também para nos aproximar, ainda que minimamente, das muitas possibilidades do que somos.

Para compreendermos a efetivação da experiência estética, é importante a inserção de um construto de leitor real, de carne e osso. Leitor cujas características cognitivas, afetivas, emocionais, sociais, históricas e políticas sejam consideradas. Um estudo metateórico alicerçado na teoria vigotskiana promoveu uma incursão fulcral de conceitos importantes na concepção do leitor real na Teoria do Efeito Estético (SANTOS, 2007).

A teorização vigotskiana sobre mediação social, Nível de Desenvolvimento Real (NDR), Nível de Desenvolvimento Potencial (NDP), Zona de Desenvolvimento Proximal (ZDP), somente para listar os mais conspícuos conceitos, podem ser associados à metáfora da interação texto-leitor que fecharia o sistema da Teoria do Efeito Estético. 
Vigotski entende a mediação social como interferência necessária entre o sujeito cognoscente e o objeto de conhecimento. O desenvolvimento e a aprendizagem são, para ele, sempre mediados. A mediação pode ser feita através de instrumentos físicos, como uma caneta que medeia nossa ação de escrever sobre uma folha de papel, ou instrumentos psicológicos, quando as ferramentas físicas são internalizadas, também denominadas de signos. Para o autor russo, desenvolvemo-nos de fora para dentro, do social para o individual, do externo para o interno.

$\mathrm{Na}$ convivência social, apreendemos o significado da palavra ou das coisas e, ao internalizarmos tal significado, temos o sentido. Assim, o significado é de teor cognitivo, enquanto o sentido é de naipe afetivo. Se a palavra "carro" tem um significado comum de meio de transporte, o seu sentido muda de acordo com o modo que foi internalizado individualmente. Qual o sentido de "carro" para um mecânico, um motorista, um piloto de Fórmula 1 ou alguém que sofreu um trágico acidente? Assim, o significado é apenas uma vertente dentro de uma gama de sentidos que a palavra ou coisa pode ter.

Construímos algo no nível interpessoal e, posteriormente, convertemos para o nível intrapessoal. A linguagem é o nosso maior acervo de instrumentos psicológicos, pois, através dela, mediamos nossos pensamentos e ações (VIGOSTSKI, 1993).

Para falar em desenvolvimento, Vigotski estipulou dois níveis: o Nível de Desenvolvimento Real (NDR), marcando o que a pessoa já consegue fazer sozinha, e o Nível de Desenvolvimento Potencial (NDP), abrangendo as ações que a pessoa poderá vir a fazer se tiver as necessárias mediações. Entre um nível e outro, temos uma faixa denominada de Zona de Desenvolvimento Proximal (ZDP). É nessa faixa que as mediações sociais ocorrem. Assim, através da mediação social, um indivíduo se desloca do NDR ao NDP, evidentemente que em um movimento dialético. Esse NDP passa a ser NDR, e outro Nível de Desenvolvimento Potencial será lançado à frente. Desse modo, as Zonas de Desenvolvimento Proximais são dialéticas, dinâmicas — pois estão sempre em constante mudança - e complexas. Possuímos uma ZDP para cada conteúdo, habilidade que precisamos desenvolver ou aprender (SANTOS, 2011). Esses conceitos brevemente discorridos podem ser associados aos processos descritos por W. Iser para o que ocorre em nossa mente durante a leitura de textos ficcionais.

\section{Associação entre conceitos de Iser e Vigotski: a chave para a construção do sentido}

A associação entre os conceitos vigotskianos e os iserianos fornecem um amparo heurístico para compreensão do conceito de leitor real que se põe em implicitude em busca da formulação da obra. Conforme Santos, 
[a] consideração do binômio sentido/significação como ponto de cruzamento entre as teorizações de Iser e Vygotsky, mostra-nos que a relação entre aprendizagem e desenvolvimento, onde a primeira alavanca o segundo, é análoga à relação iseriana entre formulação do objeto estético e significação que promove um salto na experiência do leitor. Formular sentido de um texto é aprender sobre esse texto e sobre nós mesmos. (2009, p. 241).

Para Iser, quando formulamos o objeto estético, ou seja, construímos o sentido do texto, damos uma significação para nossas vidas. Sentido para Vigotski, portanto, é análogo à significação para Iser.

Continuando nossa associação, observamos que o leitor implícito, cunhado por Iser, que se trata da estrutura apelativa do texto, pode ser perfilado ao conceito de mediação de Vigotski. A estrutura funciona como mediadora para o leitor em processo de formulação do objeto estético, a saber, o sentido. É o leitor implícito que medeia a construção de sentido pelo leitor real.

Ao considerarmos o leitor real, compreendemos que ele só conseguirá se pôr em implicitude se o texto estiver em sua Zona de Desenvolvimento Proximal, ou seja, precisa partir do conhecimento prévio do leitor e impulsioná-lo para atingir o que ainda não sabe. Caso contrário, se a estrutura textual considerasse apenas o sabido pelo leitor - o seu NDR - ele não se emanciparia. Se o texto, por sua vez, estivesse acima do seu NDP, ele igualmente não conseguiria se pôr em implicitude e, do mesmo modo, fracassaria na tarefa de construir sentido. O conceito de repertório do texto

consistirá no conjunto formado por aqueles elementos que escapolem à imanência do texto. Ele é apresentado quando o texto revela algo previamente familiar, não somente relacionado a textos de outras épocas, mas também a normas sociais e históricas e ao contexto histórico-cultural, no sentido mais abrangente. (SANTOS, 2009, p. 102).

Tal conceito de repertório pode ser associado ao NDR do leitor: ambos são pontos de partida. No primeiro, consideramos o texto; no segundo, o leitor. Após essa entrada no texto, o leitor depara-se com os vazios que, segundo Iser (1978), são constituintes do texto. Os vazios exigem uma combinação, preenchimento, articulação, pois eles interrompem a conectabilidade do texto. Iser denominou de quebra da good continuation, termo inspirado na psicologia da Gestalt, quando a conectabilidade esperada pelo leitor é rompida. Assim, mais um momento em que podemos fazer uma conexão biunívoca entre o ideário de Iser e o de Vigotski, no que diz respeito a vazios, uma vez que

[n]ão é apenas a existência de lugares vazios que incita o leitor a um preenchimento: o modo como os vazios são apresentados informa ao leitor sobre sua ação cognitiva. Os vazios podem ajudar ou emperrar a efetivação da experiência estética, se não estiverem em consonância com a ZDP de seus leitores. (SANTOS, 2009, p. 241). 
Ora, se os vazios estiverem fora da Zona de Desenvolvimento Proximal do leitor, ele poderá ser expulso da leitura, assim como é também possível que os vazios estejam em sua estrutura cognitiva, incapacitando-o de, pelo menos naquele momento, construir o sentido daquele texto. Nesse caso, precisará adquirir algumas habilidades, requisitos, para voltar a se embrenhar no dado texto, enxergando, em momento posterior, os seus vazios e podendo articulá-los para formular o objeto estético.

Em continuidade à relação biunívoca que estabelecemos entre os principais conceitos de Vigotski e Iser, apontamos as estratégias textuais destinadas à compreensão: a perspectiva do narrador, a do enredo, a do personagem e a da ficção do leitor. A estrutura que coordena e regula a perspectividade interna do texto é denominada de Tema e Horizonte. Enquanto o tema concerne à perspectiva em foco no momento, o horizonte diz respeito à perspectiva que ficou como pano de fundo, anteriormente tema. Tema e horizonte alternam-se entre foco e fundo.

A interação entre perspectivas e leitor (real), na contraposição de tema e de horizonte,
cria Níveis de Desenvolvimento Potencial diferenciados de acordo com seus diversos
leitores, assim podemos inferir que a leitura de literatura cria Níveis de
Desenvolvimento nessa área, alargando as ZDPs e propulsionando os Níveis de
Desenvolvimento Potencial para adiante. Implicações para a formação de leitores de
literatura poderiam ser pensadas a partir desse tópico, como também o caminho
inverso, a influência da literatura nos conceitos da psicologia cognitiva. (SANTOS,
2009, p. 241).

Tendo visto, embora de modo sintético e a título de exemplo, a associação possível entre alguns dos principais conceitos de Iser e os de Vigotski para a compreensão de um leitor real que aceita entrar em implicitude no texto na busca de construção do seu sentido, podemos nos aproximar agora da Antropologia Literária, prolongamento da Teoria do Efeito Estético.

Como work in progress, a Antropologia Literária ainda possui muitas perguntas para elaborar, e faz-se necessário delimitar melhor seu campo teórico. Sua premissa de que ficcionalizar é uma necessidade humana é, em sua essência, interdisciplinar. O trabalho intelectual interdisciplinar já é conhecido no pensamento iseriano. É justamente essa característica que nos permite vincular a psicologia cognitiva a ela, assim como, outrora, o próprio W. Iser aliou a sua Teoria do Efeito Estético a vários conceitos advindos de outras ciências ou disciplinas.

Desse modo, quer seja por meio de uma Teoria do Efeito Estético, quer seja por meio de uma Antropologia Literária, é inegável a contribuição iseriana à teoria e crítica literárias, de forma que torna seu mentor um homem intelectual admirado e respeitado até por seus mais ferrenhos antagonistas. Associar a teoria vigotskiana à iseriana, com o objetivo de fornecer 
suporte heurístico para a inserção de um conceito de leitor real, parece-nos uma ideia pertinente e instigante para a pesquisa em leitura literária.

Ao passo que conceitos da teoria iseriana como vazios, ficcionalização, quebra da good continuation, repertório, estrutura de tema e horizonte, dentre outros, puderam ser ancorados em um leitor com Nível de Desenvolvimento Real, que busca atualizar sua potência por meio da experiência estética, como já explicado. Desse modo, é possível inserir o conceito de recursive looping. De acordo com Iser, o looping seria

[um] sistema de feedback [que] se desenvolve como um intercâmbio entre o que sai (output) e o que entra (input), durante o qual a projeção é corrigida, caso não tenha conseguido ajustar-se àquilo a que visava. Ocorre assim uma dupla correção: o feed forward retorna como um feedback loop alterado, que, por sua vez, alimenta um output revisto (1999c, p.154).

A dupla correção explicitada no excerto acima, seria, portanto, a estratégia adequada para operar com a interpretação, entendida como tradução entre as culturas. Ainda se pode recorrer ao looping na tradução de linguagens e nas análises literárias, nas quais a nossa experiência estética permite articular a estrutura de tema e de horizonte, como em uma espiral onde se passa pelo mesmo lugar várias vezes, mas, a cada turno, novas informações são inseridas na leitura e compreensão.

$\mathrm{O}$ recursive looping pode ser considerado como a metáfora para o que acontece com o leitor real ao ficcionalizar dentro de sua Zona de Desenvolvimento Proximal: a cada leitura, ele incorpora novos elementos, de modo a ampliar seu repertório, propiciando-lhe condições cognitivas mais abrangentes para leituras mais complexas, emancipando-se.

Empenhada no engajamento do leitor em uma atividade que envolve um "fingimento", a teoria iseriana trata dos atos impulsionados por tal simulação, mesmo referindo-se a um evento ilusório. O envolvimento em "atos de fingir" denuncia nosso gosto na vivência de ilusões (ISER, 1999). Essa vivência, por assim dizer, pode revelar algo sobre nós. Os seres humanos, conforme discorremos, demonstram precisar desse tipo de artifício, por isso, Wolfgang Iser afirma que

[e]m face dessa aparente necessidade, ou se reconhece que uma teoria do efeito não pode mais explicá-la, ou se amplia essa mesma teoria a tal ponto, que o estudo do processamento do texto dá lugar a um estudo do que o meio pode revelar acerca das disposições que caracterizam a constituição humana. Nesse segundo caso, uma Antropologia Literária seria um desdobramento direto da Teoria do Efeito Estético, uma vez que procura responder a perguntas que esta última formulou, mas deixou sem resposta. (ISER, 1999, p. 66).

São distintos três atos de fingir no texto literário: a seleção, a combinação e autoevidenciação ou autodesnudamento (ocasionando o como se). Iser (1978) sumariza a 
seleção como incorporação de elementos retirados dos campos de referência extratextuais, podendo também invadir outros textos, engendrando a intertextualidade, ao passo que aumenta a complexidade do jogo. A combinação, por sua vez, atravessa fronteiras intratextuais de significados lexicais a fronteiras transgredidas pelos protagonistas. A autoevidenciação ou autodesnudamento, finalmente, ocasiona um ato de duplicação: o como se. A seleção e a combinação tiveram sua formulação iniciada no Ato da Leitura. Posteriormente, foram mais bem configuradas em The Fictive and the Imaginary: charting Literary Antrhopology (1993a), ao passo que se acresceu o autodesnudamento, enquanto as noções sobre o imaginário tomaram cada vez mais espaço nas últimas elaborações do teórico alemão.

Transpondo esse raciocínio para uma forma antropológica de pensar a relação triádica, é compreensível que, a fim de realizar a (necessária) mobilização do nosso imaginário, seja preciso o fictício. É o fictício, então, o elemento ativador, provocador de movimentos do imaginário. Desse modo, a ficcionalidade só pode ser um ato consciente promovido por indeterminações, e, sem o imaginário, não teríamos como preencher a moldura conformada pelo ato de fingir. Para Iser (1978), temos uma encenação (enactment) do processo de "modos de construir, de fabricar mundos" (ways of worldmaking), cuja forma paradigmática reside na literatura, quando o fictício interage com o imaginário.

Em síntese, movemo-nos do esteio do leitor implícito - enquanto estrutura apelativa do texto, ou seja, o leitor como implicado, emaranhado no texto, sendo, portanto, o próprio texto, - para o leitor real, aquele que respira. Ao leitor implícito, fica, entretanto, a tarefa de ser o que é: estrutura textual.

Ora, a incursão do conceito de leitor real não seria possível apenas do ponto de vista de uma teoria literária. A interdisciplinaridade já mencionada da teoria iseriana é fantástica. Como dito, o próprio Iser utilizou-se de diversas áreas, inclusive da psicologia - como foi o caso da psicologia social, da psicologia da Gestalt, do jogo no e do texto extraído do pensamento de Piaget (1990), das estruturas mentais exploradas por Bruner (1997), entre outros sistemas teóricos relacionados à teoria do efeito - para formulação do objeto estético, a saber, a obra. O modo de elaborar teoria de Iser favorece, assim, a associação que fizemos na seção acima, e tal remodelação teórica repercutiu na construção de mapeamento da experiência estética que vem sendo vivenciada pelas alunas e pelos alunos de diversos projetos da graduação e da PósGraduação em Letras.

Se os textos ficcionais favorecem a criação de mundos que sabemos não existir, por que, mesmo tendo consciência disso, nos interessamos em adentrar em atos de fingir? Para a Antropologia Literária, repetimos, ficcionalizar é uma necessidade humana. Precisamos 
interpretar e preencher vazios dos textos, dos filmes, das artes plásticas e cênicas, da música, da dança, das situações cotidianas e, principalmente, de dentro de nós. Buscamos interpretar nossos vazios, estejam eles onde estiverem, por mais paradoxal que seja o ato de identificar um vazio, pois, ao fazê-lo, a ausência se torna presença.

Durante a docência no ensino superior, lemos autorretratos, memoriais e textos pessoais descritivos de personalidade para apresentação dos alunos no início de cada semestre do componente curricular Fundamentos Psicológicos da Educação. Na maioria deles, sobremodo nos de estudantes de Letras, encontramos evidências para acreditar que a literatura permite, nos termos de Iser, experimentarmos diversas possibilidades de nós.

Em tempos de reclusão, consequência da pandemia que ora assola o planeta e, sobremodo, nosso país, transtornos psíquicos como depressão, síndrome de pânico, ansiedade generalizada e fobias têm se elevado exponencialmente. Em casos assim, a literatura pode nos tirar do mundo real, nos "limpar e preencher" e nos devolver fortalecidos para o nosso contexto, propulsandonos, desse modo, para vida.

\section{Emancipação: para além do oxigênio}

Sobre a função da literatura, à sua serventia, Yves de La Taille (1999) respondeu que, em termos concretos, ela não teria utilidade para coisa alguma. Nossa vida, todavia, é mais que concretude e, assim, paradoxalmente, sem função específica ou concreta como a de fornecer oxigênio, ela nos dá vontade de querer respirar.

Iser (2008) cita o filósofo alemão Helmuth Plessner, corroborando o dramaturgo e escritor irlandês Samuel Beckett: "Eu sou, mas eu não tenho a mim mesmo" (tradução nossa) ${ }^{2}$. Iser explica que 'ter' aqui significa conhecer o que é ser, o que requereria uma posição transcendental a fim de consolidar a certeza autoevidente de nossa existência com todas as suas implicações, significado/significação e sentido. “O fato de que nós parecemos necessitar desse estado extasiado de estar ao lado, fora e além de nós mesmos, cooptados e ainda desanexados de nossa própria realidade, deriva de nossa inabilidade para estarmos presentes em nós mesmos" (ISER, 2008, p. 24, tradução nossa) ${ }^{3}$.

Nós não suportamos ficar dentro de nós, da única possibilidade de nós, porque, para isso, precisaríamos ligar o início ao fim, o nascimento à morte. Ao fazer essa ligação, inevitável e dolorosamente, passaríamos pela questão imponderável do sentido da vida. Contentarmo-nos

\footnotetext{
${ }^{2}$ No original: “I am, but I do not have myself” (BECKETT, 1956, p. 18 apud ISER, 2008, p. 24)

${ }^{3}$ No original: "The fact that we seem to need this 'ecstatic' state of being beside, outside, and beyond ourselves, caught up in and yet detached from our own reality, derives from our inability to be present to ourselves".
} 
com uma única possibilidade de nós antecipa a morte em todos os seus imprevisíveis sentidos. Somos o que somos mais todas as possibilidades de sermos, incluindo, em um oximoro transcendental, aquelas que excluímos.

Por amor às possibilidades de nós mesmos, de querermos ser para nós e para quem e o que amamos, embrenhamo-nos em ficção. "O amor é, provavelmente, a mais intensa das experiências evidenciais e ele é também o tópico central da encenação em literatura" (ISER, 2008 , p. 26, tradução nossa) ${ }^{4}$. A cada encenação produzida em nossa experiência estética, decolamos ou mergulhamos, em ascendente ou descendente vertical. A vertigem de experimentar o que poderíamos ser se quiséssemos, o que poderíamos ser e não quisemos, o que queríamos ser e não podemos, o que somos e não queremos, o que somos e ainda queremos mais, permite-nos entrar em um caleidoscópio que reflete múltiplas imagens de nossas infindas possibilidades. Todas as possibilidades abertas, porém, estão em falta com a autenticidade, porque nós não nos temos. Para Iser (2008, p. 27, tradução nossa), “O que é notável, ainda, é o fato de que nossa consciência dessa inautenticidade não nos impede de continuarmos a ficcionalizar" $"$.

A experiência estética pode nos liberar de nossas amarras, mesmo que temporariamente. Esse tempo fora de nós ou além de nós ou dentro do que poderíamos ser, fortalece nossa infraestrutura psíquica, nos emancipa cognitiva e metacognitivamente. É mais do que ativar nossos processos cognitivos, trata-se de gerenciá-los e, nesse sentido, isso significa estarmos no centro de nós, com o leme nas mãos para que os reveses da vida atual não nos automatize, não nos robotize, não transforme a nós e a quem amamos em clusters de algoritmos.

Somente estando em nós, poderemos dar conta dos outros ao nosso redor, admirarmos as diferenças e apararmos as desigualdades. Só reconhecemos no outro o que conhecemos em nós. É urgente levar essa perspectiva para a escola e para a vida, pois não basta ter oxigênio, é preciso que desejemos inspirá-lo.

\section{Considerações finais ou luz(cidez) mesmo que tênue}

Neste artigo, refletimos sobre a relevância dos atos de ficcionalizar e a emancipação do leitor que, em tempos de reclusão ocasionada por uma pandemia, torna-se ainda mais relevante.

\footnotetext{
${ }^{4}$ No original: "Love is probably the most intense o these experiences, and it is also the central topic of staging in literature".

${ }^{5}$ No original: "What is remarkable, though, is the fact that our awareness of this inauthenticity does not stop us from continuing to fictionalize”.
} 
Em seguida, discutimos a noção de complementar e suplementar em relação às teorias da recepção e do efeito estético, defendendo o caráter suplementar de ambas as teorias.

Em seguida, circunscrevemos a discussão sobre os atos de ficcionalizar e a emancipação do leitor na tríade teórica composta pela Teoria Histórico-Cultural, do psicólogo russo Lev. S. Vigotski, a Teoria do Efeito Estético, e seu prolongamento, a Antropologia Literária, ambas de Wolfgang Iser. Foi dissertado sobre a experiência estética, a importância da incursão do conceito de leitor real e a conexão biunívoca entre alguns dos principais conceitos da teoria vigotskiana e iseriana.

Por conseguinte, afunilamos para a Antropologia Literária, expondo conceitos centrais como os atos de fingir ou ficcionalizar no texto literário: a seleção, a combinação e autoevidenciação ou autodesnudamento.

Fechamos nosso raciocínio, retornando ao panorama atual e à relevância dos atos de ficcionalizar em literatura como espaço para acreditarmos no fingimento de termos a nós mesmos e, de algum modo, nos emancipar, visualizando um feixe de luz em tempos tão sombrios.

\section{Referências}

BRUNER, Jerome. Realidade mental, mundos possíveis. Trad. de Marcos A. G. Domingues. Porto Alegre: ArtMed, 1997.

CANDIDO, Antonio. O direito à literatura. In: Vários Escritos. Rio de Janeiro: Ouro sobre Azul, 2011.

ECO, Umberto. Interpretação e Superinterpretação. Trad. M. F. São Paulo: Martins Fontes, 1993.

ISER, Wolfgang. A indeterminação e a resposta do leitor na prosa de ficção. Trad. Maria Angela Aguiar. Porto Alegre: Publicação do Centro de Pesquisas Literárias do Curso de PósGraduação em Letras da PCRS, 1971.

ISER, Wolfgang. The Implied Reader: patterns of communication in prose fiction from Bunyan to Beckett. Baltimore and London: Johns Hopkins University Press, 1974.

ISER, Wolfgang. The act of Reading: a theory of aesthetic response. Baltimore and London: The johns Hopkins University Press, 1978.

ISER, Wolfgang. The Fictive and the Imaginary: charting Literary Antrhopology. Baltimore and LondonThe Johns Hopkins University Press, 1993a.

ISER, Wolfgang. Prospecting: from reader response to literary anthropology. London: The Jonhs Hopkins University Press, $1993 b$. 
ISER, Wolfgang. O que é Antropologia Literária? In: ROCHA, J. C. de C. (Org.). Teoria da Ficção: indagações à obra de Wolfgang Iser. Trad. de Bluma W. Vilar e João C. de C. Rocha. Rio de Janeiro: EdUERJ, 1999.

ISER, Wolfgang. How to do theory. Malden, MA: Blackwell Publishing, 2006.

ISER, Wolfgang. Stepping forward: essays, lectures and interviewes. 2a ed. Maidstone, UK: British Library in Publication, 2008.

JAUSS, Hans Robert. A história da literatura como provocação à teoria literária. Trad. de Sérgio Tellaroli. São Paulo: Editora Ática, 1994, p. 23.

LARROSA, Jorge. Pedagogia Profana: danças, piruetas e mascaradas. Trad. de Alfredo Veiga-Neto. 4. ed. Belo Horizonte: Autêntica, 2006.

PIAGET, Jean. A formação do símbolo na criança: imitação, jogo e sonho. Imagem e representação. Trad. Editions Delachaux et Niestlé. 3. ed. Rio de Janeiro: Livros Técnicos e Científicos Editora, 1990.

SANTOS, Carmen Sevilla Gonçalves dos. Teoria do Efeito Estético e Teoria Históricocultural: o leitor como interface. Tese de doutorado apresentada à Universidade Federal de Pernambuco. Recife, 2007.

SANTOS, Carmen Sevilla Gonçalves dos. Teoria do Efeito Estético e Teoria Históricocultural: o leitor como interface. Coleção Teses. Recife: Bagaço, 2009.

SANTOS, Carmen Sevilla Gonçalves dos. Psicologia da Educação e Literatura: a perspectiva sociocultural como link. In: Carmen Sevilla G. dos Santos; Luiz Gonzaga Gonçalves (Autores). Educação: links filosóficos e psicológicos. Coleção todas as Letras. João Pessoa: Editora da UFPB, 2011.

SANTOS, Carmen Sevilla Gonçalves dos, et al. Empoderando licenciandos em Letras: antropologia literária e habilidades sociais educativas. Relatório técnico científico apresentado ao PROLICEN- UFPB, 2014.

SANTOS, Carmen Sevilla Gonçalves dos, et al. Empoderando licenciandos em Letras: antropologia literária e habilidades sociais educativas. Relatório técnico científico de projeto continuado apresentado ao PROLICEN- UFPB, 2015.

SANTOS, Carmen Sevilla Gonçalves dos, et al. Da ficcionalização em cinema para o ensino-aprendizagem da leitura literária no Ensino Médio: a criação de um Roteiro Didático Metaprocedimental. Relatório técnico científico apresentado ao PROLICEN-UFPB, 2017.

SANTOS, Carmen Sevilla Gonçalves dos, et al. Da ficcionalização em cinema para o ensino-aprendizagem da leitura literária no Ensino Médio: a criação de um Roteiro Didático Metaprocedimental. Relatório técnico científico de projeto continuado apresentado ao PROLICEN-UFPB, 2018. 
SANTOS, Carmen Sevilla Gonçalves dos, et al. Da ficcionalização em cinema para o ensino-aprendizagem da leitura literária no Ensino Médio: a criação de um Roteiro Didático Metaprocedimental. Relatório técnico científico de projeto continuado apresentado ao PROLICEN-UFPB, 2019.

SANTOS, Carmen Sevilla Gonçalves dos. Por que (não) precisamos ler (e ensinar) literatura? In: Literatura e ensino: reflexões e propostas. Luiz. A. de Sá Júnior e Andrey Pereira de Oliveira (Orgs.). Coleção Ciências da Linguagem Aplicadas ao Ensino. Natal: Editora da UFRN, 2014.

SCHWAB, Gabrielle. Se ao menos eu não tivesse de manifestar-me: a estética da negatividade de Wolfgang Iser. In: ROCHA, J. C. de C. (Org.). Teoria da Ficção: indagações à obra de Wolfgang Iser. Trad. de Bluma W. Vilar e João C. de C. Rocha. Rio de Janeiro: EdUERJ, 1999.

VIGOTSKI, Lev Semenovich. Pensamento e Linguagem. Trad. de Jéferson Luiz Camargo. São Paulo: Martins Fontes, 1993.

YVES, de La Taille. Autoridade na escola. In: Na escola: alternativas teóricas e práticas. Júlio Groppa Aquino. (Org.) São Paulo: Summus, 1999.

Recebido em: 18/05/2020 Aceito para publicação em: 18/08/2020 